\title{
Stressful life events and the risk of initial central nervous system
}

\section{demyelination}

Saul, A (Hons) ${ }^{1}$, Ponsonby A-L (MBBS PhD) ${ }^{2}$, Lucas RM (MBChB MPH\&TM PhD) ${ }^{3}$, Taylor BV $(\mathrm{MD})^{1}$, Simpson, Jr. S (PhD, MPH $)^{1}$, Valery PC $(\mathrm{PhD})^{4}$, Dwyer T (MD) ${ }^{5}$, Kilpatrick TJ (MD) ${ }^{6}$, Pender MP $(\mathrm{MD})^{7}$, van der Mei IAF $(\mathrm{PhD})^{1}$

1. Menzies Institute for Medical Research, Hobart, Australia

2. Murdoch Childrens Research Institute, Melbourne, Australia

3. National Centre for Epidemiology and Population Health, Research School of Population Health, The Australian National University, Canberra, Australia

4. QIMR Berghofer Medical Research Institute, Brisbane, Australia

5. International Agency for Research on Cancer, Lyon, France

6. Centre for Neuroscience, The University of Melbourne, Melbourne, Australia

7. School of Medicine, The University of Queensland, Brisbane, Australia

Running head: Stressful life events and CNS demyelination.

Characters title: 84

Characters running head: 57

Number of words in abstract: 198

Number of words body manuscript: 2889

Number of figures: 0

Number tables: 4

Number references: 28

\section{Corresponding author:}

I.A.F. van der Mei, Menzies Institute for Medical Research, Private Bag 23, Hobart, Tasmania, Australia 7001; Email: Ingrid.vanderMei@utas.edu.au; Tel +61 36226 7700, Fax +61 3 62267704

Key words:

First demyelinating event, first clinical diagnosis, stress, stressful life events, Multiple Sclerosis, risk factors 


\begin{abstract}
Background: There is substantial evidence that stress increases Multiple Sclerosis disease activity, but limited evidence on its association with the onset of Multiple Sclerosis.

Objective: To examine the association between stressful life events and risk of first demyelinating event (FDE).
\end{abstract}

Methods: This was a multicentre incident case-control study. Cases ( $n=282$ with first diagnosis of central nervous system (CNS) demyelination, including n=216 with "classic FDE") were aged 1859 years. Controls without CNS demyelination $(n=558)$ were matched to cases on age, sex, and study region. Stressful life events were assessed using a questionnaire based on the Social Readjustment Rating Scale.

\title{
Results:
}

Those who suffered from a serious illness in the previous 12 months were more likely to have a FDE (OR $2.35(1.36,4.06) p=0.002)$, and when we limited our reference group to those who had no stressful life events, the magnitude of effect became stronger (OR $5.41(1.80,16.28))$. Total stress number and stress load were not convincingly associated with the risk of an FDE.

Conclusion: Cases were more likely to report a serious illness in the previous 12 months, which could suggest that a non-specific illness provides an additional strain to an already predisposed immune system. 


\section{Introduction}

Multiple sclerosis (MS) is a complex autoimmune disorder of the central nervous system (CNS). ${ }^{1,2}$ Symptoms of the disease appear to be individualised and include alterations in sensory/visual systems, sexual dysfunction, and abnormalities in gait or bowel function. ${ }^{3}$ As the aetiology of MS is still not fully understood, research has focused on various genetic and environmental influences that trigger the onset and progression of the disease. ${ }^{2}$ By understanding how these factors alter risk and progression of MS, advancements in preventing the disease and the progression may be achievable. ${ }^{4}$

It was Charcot in the 1800s who first related oxidative stress to MS. There is substantial evidence that stress increases MS disease activity as measured by the number or risk of relapses, gadoliniumenhanced lesions and T2 weighted lesions on magnetic resonance imaging scans. ${ }^{2,5-7}$ A metaanalysis conducted by Mohr et al. ${ }^{8}$ in 2004 reviewed 14 studies on the association between stressful life events (SLEs) and relapses and found that SLEs increased the risk of a relapse (Cohen's $d=$ $0.53,95 \%$ confidence interval 0.40 to $0.65, \mathrm{P}<0.0001)$. A more recent review shows that studies since 2004 confirm the association between SLEs and relapse. ${ }^{2}$ Stress is known to dysregulate the Hypothalamic-Pituitary-Adrenal axis (HPA axis) and there is evidence that people with MS have a hyper-responsive HPA axis, with greater cortisol levels in plasma and cerebrospinal fluid, enlarged adrenal glands and increased amounts of corticotrophin releasing neurons. ${ }^{9-13}$

The literature on the association between SLEs and the onset of MS is more limited, ${ }^{2,14-18}$ but most studies have found that MS patients more often report a stressful life event prior to onset of first symptom or diagnosis of MS compared to controls. ${ }^{18} 14,15$ Some of these studies were relatively small, potentially prone to selection bias, ${ }^{14,19}$ did not assess confounding variables, ${ }^{19}$ and some assessed stressful life events prior to diagnosis rather than prior to symptom onset, ${ }^{15}$ and thus the temporality in relation to disease onset is difficult to interpret. Using an incident case-control study of cases with a first clinical diagnosis of demyelination and detailed data on confounding variables, we aimed to examine the relationship between SLEs in the previous 12 months and the onset of a first demyelinating event (FDE). 


\section{Materials and Methods}

\section{Participant characteristics}

The Ausimmune Study is a multi-centre case-control study in four regions in Australia: Brisbane City (27 $7^{\circ}$ South), Newscastle City and surrounds (33 South), Geelong City and the western districts of Victoria ( $37^{\circ}$ South) and the island of Tasmania ( $43^{\circ}$ South). These specified geographical regions were defined by participant postcodes and were chosen to achieve an adequately sized, source population that were likely to convert within three years. Participants were aged between 18-59 years and resident within a study region between $1^{\text {st }}$ November 2003 and 31 December 2006. The Ausimmune Study was approved by the nine regional Human Research Ethics Committees and all participants gave written informed consent.

Cases had an incident first clinical diagnosis of central nervous system demyelination (FCD), including classic FDEs (defined as a single, first, episode of demyelination), ${ }^{20}$ primary progressive MS (PPMS), and possible subsequent events, where the historical first event had not previously been clinically diagnosed. Cases were notified to the study by medical specialists and a study neurologist confirmed the date and symptomatology of the FDE and conducted a full neurologic examination. Case clinical information was reviewed annually by the study neurologist group to assess eligibility as FDE, FCD, or PPMS. As part of the study, cases were reviewed annually for two or three years, which assisted with the case classification. Of 311 eligible cases, 282 (91\%) agreed to participate, including those presenting with a classic first demyelinating event (FDE, $\mathrm{n}=216$ ), a first diagnosis of primary progressive MS (PPMS, $n=18$ ) and those in whom, in retrospect, there had been a previous, undiagnosed, probable FDE $(n=48)$.

Controls ( $\mathrm{n}=558,60 \%$ of those contacted) were randomly selected from the Australian Electoral Roll (compulsory registration for citizens $\geq 18$ years) and matched to cases on age (within 2 years), sex, and study region. Controls were recruited and interviewed over the same period as the cases. The study information provided to participants referred to "immune diseases" broadly, not specifically to MS, with the aim of minimising recall bias. Staff was also trained not to refer to "MS" in their conversations with participants.

\section{Measurements}

SLE assessment - SLEs were assessed using a modified questionnaire based on the Social Readjustment Rating Scale by Holmes \& Rahe (SRRS) ${ }^{21}$ detailing different types of life events with varied weights of emotional impact (positive and negative). Participants were asked to report the presence/absence of each type of event within the previous 12 months e.g. "You suffered from a 
serious illness". These events involved questions relating to the participant's employment or financial issues, gaining/losing family members, changing personal circumstances (habits, lifestyle, relationships, employment), experiencing personal achievement/disappointment, health related issues, problems with the law or having a close friend/relative experience the same. Individual events based on the SRRS were recoded into larger groups based on the protocol from Warren et al. ${ }^{18}$ The total number of stressful life events was summed based on the presence/absence of 16 stressful life events. This is referred to as the stress number. To take into account that some events are more stressful than others, a total SLE load was calculated using weights from Scully et al. who developed new weights from the original SRRS, 30 years after the original weightings were developed, to allow for changes in culture. ${ }^{22}$ This is referred to as the stress load. SLE assessment data were completed for 550/558 FCD controls, 275/282 FCD cases, 393/398 FDE controls and 213/216 FDE cases.

Other measures - We collected self-reported data on history of infectious mononucleosis ("have you ever had glandular fever?"), smoking history, alcohol intake, number of live born children, physical activity and highest education level completed. Silicone skin casts were used to objectively measure cumulative past sun exposure. ${ }^{23}$ They were made on the dorsum of both hands as previously described, ${ }^{23}$ photographed and graded on a scale from 1 to 6 , representing minimal to severe actinic skin damage, respectively. Skin reflectance on the buttock (non-sun exposed site) was measured using a hand-held spectrophotometer (Minolta CM2500d) to estimate cutaneous melanin density. ${ }^{23}$ Among cases, disability (EDSS and its functional system scores) was assessed by a study neurologist. Most participants provided a blood sample (94\%), from which $1 \mathrm{~mL}$ serum aliquots were stored at $-80^{\circ} \mathrm{C}$ and analysed after study completion. Concentration of 25 -hydroxyvitamin $\mathrm{D}$ $(25(\mathrm{OH}) \mathrm{D})$, the diagnostic metabolite of vitamin $\mathrm{D}$, was measured using liquid chromatography tandem mass spectrometry, with a high inter-batch agreement for duplicate samples $(\mathrm{n}=39$ pairs, intraclass correlation=0.89).. HLA-DR15 genotype was measured using the proxy SNP rs9271366. Anti-EBNA IgG antibody titers were measured on a sub-sample ( $\mathrm{n}=206$ cases, $\mathrm{n}=217$ controls), using an immunofluorescence assay as described previously. ${ }^{24}$

\section{Statistical Analysis}

All analysis was completed using STATA/IC 12.1. Conditional logistic regression was used to account for the case control matching. To allow for seasonal effects of 25(OH)D level on disease onset, we fitted region-specific sine and cosine curves ${ }^{25}$ to the individual data points of $25(\mathrm{OH}) \mathrm{D}$ level and used these curves to project $25(\mathrm{OH}) \mathrm{D}$ levels of the controls to the blood collection date of the matched case. Actinic damage, 25(OH)D level, infectious mononucleosis, anti-EBNA IgG 
level, ever smoking, HLA-DR15 genotype were examined as potential confounders as these are known to be associated with MS as risk factors. We also considered a number of other factors such as education level, alcohol intake, physical activity, skin melanin density, body mass index, and number of live born children. 


\section{Results}

The characteristics of the 282 FCD and 216 classic FDE cases, and that of the matched controls, are shown in Table 1. The mean age of the FDE cases was 37.5 years and $76.9 \%$ were female.

\section{Specific significant life events}

Table 2 shows associations between each individual SLE and FDE risk. Compared to those who did not suffer from a serious illness in the previous 12 months, those who suffered from a serious illness were more likely to have a FDE (OR $2.35(1.36,4.06))$. When we limited our reference group to those who had not had any SLE in the previous 12 months compared to their matched controls (34 cases, 74 controls), the magnitude of effect became stronger (OR $5.41(1.80,16.28)$ ). The association with serious illness persisted when we expanded our sample to include those with PPMS and those with a previous, undiagnosed probable FDE (First Clinical Diagnosis) (Adjusted OR $2.43(1.45,4.08) \mathrm{p}<0.01)$. Table 3 groups individual SLEs into larger groups. Participants who reported a SLE within the category of "Personal illness/injury or illness/injury of a close family member or friend" were 1.5 times more likely to experience a classic FDE when compared to participants that did not experience these events. This magnitude of effect was stronger again when we limited our reference group to those who did not experience any SLE in the previous 12 months (Adjusted OR $2.01(1.09,3.72)$ ). When we examined whether the time lag between the FDE event and the interview ( $>90$ days or $\leq 90$ days) influenced the results, we found no significant difference ( $\leq 90$ days: Adjusted OR $2.55(0.61,10.64)$; $>90$ days: OR $2.02(1.01,4.04), p=0.74)$. There was no significant interaction with sex $(p=0.65)$ or age $(p=0.86)$, or whether people already had any disability (based on EDSS) $(p=0.36)$ or its individual function system scores $(\mathrm{p}>0.18)$ ).

\section{Total stress number and load}

Total stress number in the previous 12 months was weakly associated with FDE, but after adjustment for physical activity, the magnitude of effect strengthened and a dose-response association was observed (Table 4). Other potential confounders did not significantly alter the association or were not associated with the exposure variable. There was also some association with stress load, but this was not significant (Table 4). Also, when we expanded our sample to include those with PPMS and those with a previous, undiagnosed probable FDE, no significant associations were observed both for stress number (test for trend: OR $1.10(0.95,1.29) \mathrm{p}=0.21)$ and stress load (test for trend: OR $1.10(0.92,1.32) \mathrm{p}=0.29)$. No significant interactions with sex, age, or lag time were observed $(p>0.25)$. When we examined interactions between total stress number and level of current disability (EDSS) or its individual function system scores, we found a consistent pattern 
(although non-significant) that the effects were stronger among those with some disability in the functional system scores, indicating that this group might have slightly increased the reporting of stressful life events or had a true increase in events as a result of the accrued disability. 


\section{Discussion}

We found that those who reported a serious illness (excluding the event that brought them into the study) in the twelve months prior to interview had a more than 2-fold higher risk of FDE compared to those who did not experience a serious illness. This association became stronger when we limited our reference group to those who did not experience any significant life events. None of the other event types were significantly associated with FDE and combining all events to a total stress number and total stress load in the twelve months prior to interview was also not convincingly associated with the risk of an FDE.

While we found some evidence of an association for total stress number and load, the magnitude of effect was moderate for stress number and weak for stress load. The associations were no longer apparent when we included people with PPMS and those with a previous undiagnosed FDE. The fact that the effect was somewhat stronger for those who already had some disability at the interview, suggests that this group might have slightly increased the reporting of stressful life events or had a true increase in events as a result of the accrued disability. These findings are not in line with most other studies that measured stress prior to the onset of the first MS symptom. For example, Warren et al. found that cases more often experienced unwanted stress (79\%) and more stressful life events (180 events) in the two years prior to symptom onset compared to controls (54\% and 59 events, respectively). ${ }^{18}$ They observed significant differences for nearly every event group (personal illness, or illness of close family member or friend, pregnancy related problems, financial problems, marital problems, interactional problems with family members). ${ }^{18}$

Our study assumed that twelve months prior to FDE was a critical window in disease development, but this window may well be longer or shorter. Interestingly, another early case-control study measured adversity in the year prior to symptom onset and found that the six months prior to symptom onset were particularly important. ${ }^{14}$ Palumbo et al. detected a non-significant difference in the number of stressful life events in the year preceding the first symptoms when comparing $65 \mathrm{MS}$ patients to 27 patients with chronic polyneuropathies. ${ }^{19}$ Two studies have examined stress in other phases of life. A Danish record linkage study found that parents who lost a child younger than 18 years were more likely to have MS compared to parents who didn't lose a child (hazard ratio 1.5 (95\% CI 1.05 to 2.31) and the magnitude of the effect was stronger for those with more than eight years of follow-up (hazard ratio 2.25 (95\% CI 1.32 to 3.81 ). ${ }^{16}$ The Nurses Health Studies, which measured stress at home and at work in 1982 and physical and sexual abuse in childhood and adolescence in 2001, did not find associations with MS after follow-up. ${ }^{17}$ 
Our finding that those who had an FDE were more likely to have suffered from a serious illness in the previous twelve months compared to healthy controls is in line with Warren et al. ${ }^{18}$ We also found that the group "Personal illness/injury or illness/injury of a close family member or friend" were 1.5 times more likely to experience a classic FDE, and this was largely driven by the association between "personal serious illness" and FDE. Importantly, the association with a serious illness persisted when including people with PPMS and those with an undiagnosed probable FDE, and there was no difference by whether any disability had been accrued by the cases or by lag time between the FDE and interview. The finding could have a number of explanations. Firstly, a nonspecific serious illness could be a true causal factor that interacts with other known risk factors such as infection with the Epstein-Barr virus. Secondly, a non-specific serious illness could have simply resulted in an additional challenge to a predisposed immune system that may have resulted in subclinical inflammatory demyelination becoming symptomatic.

Strengths of this study are the examination of a broad spectrum of environmental factors and the fact that we assessed the association of SLEs prior to first symptom rather than prior to diagnosis. The use of incident FDE cases rather than those actually diagnosed with MS minimised diseaserelated changes in behaviour and recall, but it is still conceivable that the recent FDE event among case influenced their recall. Our study assumed that 12 months prior to FDE was a critical window, but this may be different. Also, we did not assess SLEs in earlier periods of life. Li et al. found in retrospective cohort study using data linkage that the effect of the loss of a child became more important after a longer follow-up period. ${ }^{16}$ Another study by Spitzer et al. found that childhood emotional neglect and abuse were significantly higher in the MS population when compared to the controls and that this early life stress was associated with relapses but not disability. ${ }^{26}$ Also, we examined the stress load, using load averages determined in a separate cohort ${ }^{22}$ but we did not determine the actual personal experience of the severity of the stressors or the valance of the stressors. The valance has been shown to be of relevance, with negative SLEs associated with an increased risk of gadolinium-enhanced and new/enlarging $\mathrm{T}_{2}$ lesions, while positive SLEs were associated with a reduced risk of new/enlarging $\mathrm{T}_{2}$ lesions. ${ }^{27}$ Due to referral processes and patient availability, there was always some time delay between the FDE date and the interview date, which could have resulted in some SLEs occurring in that time delay. However, when we restricted the analysis to those with a smaller time lag, the association with serious illness became stronger rather than weaker, suggesting that the temporality of the association with serious illness is correct, with serious illness preceding the FDE rather than being the consequence of the FDE. A potential weakness in our study is that the control participation rate was $60 \%$. This resulted in controls being more highly educated and of higher socioeconomic status than the general population, ${ }^{28}$ which 
could have overestimated our results as controls with a higher socioeconomic status tended to have slightly less significant life events.

In conclusion, although the literature suggests that stress appears to play an important role in MS relapses, we did not confirm that total stress number or total stress load in the prior twelve months was associated with an increased risk of FDE. We did, however, find that those who reported a serious illness in the previous 12 months were more likely to be an FDE case, possibly suggesting that the presence of this illness may directly trigger inflammatory demyelination or indirectly via a combination of factors resulted in an additional challenge to the immune system which resulted in the demyelination becoming symptomatic. 


\section{Grants and/or financial support}

This research was supported by the Australian Research Council (Future Fellowship 100100511), the National Health and Medical Research Council of Australia, Multiple Sclerosis Research Australia, the Royal Australasian College of Physicians, MS Research Australia, the US National Multiple Sclerosis Society, the Poola Foundation, the Health Research Council of New Zealand, the MS Society of Tasmania, Bayer Schering Pharma, and Biogen Idec, Inc. Funding sources did not contribute to the design and conduct of the study, management, analysis or interpretation of the data or approval of the manuscript. PC Valery and RM Lucas were supported by Australian National Health and Medical Research Council Career Development Fellowships. I van der Mei was supported by an Australian Research Council Future Fellowship. 
1. Keegan BM and Noseworthy JH. Multiple sclerosis. Annu Rev Med. 2002; 53: 285-302.

2. Artemiadis AK, Anagnostouli MC and Alexopoulos EC. Stress as a risk factor for multiple sclerosis onset or relapse: a systematic review. Neuroepidemiology. 2011; 36: 109-20.

3. Dennison L and Moss-Morris R. Cognitive-behavioral therapy: what benefits can it offer people with multiple sclerosis? Expert review of neurotherapeutics. 2010; 10: 1383-90.

4. Ebers GC, Yee IM, Sadovnick AD and Duquette P. Conjugal multiple sclerosis: populationbased prevalence and recurrence risks in offspring. Canadian Collaborative Study Group. Ann Neurol. 2000; 48: 927-31.

5. Brown RF, Tennant CC, Sharrock M, Hodgkinson S, Dunn SM and Pollard JD. Relationship between stress and relapse in multiple sclerosis: part II. Direct and indirect relationships. Multiple sclerosis. 2006; 12: 465-75.

6. Potagas C, Mitsonis C, Watier L, et al. Influence of anxiety and reported stressful life events on relapses in multiple sclerosis: a prospective study. Multiple sclerosis. 2008; 14: 1262-8.

7. Oveisgharan S, Hosseini S, Arbabi M and Nafissi S. Stress differentially predicts multiple sclerosis relapses. Neurology Asia. 2014; 19: 53-8.

8. Mohr DC, Hart SL, Julian L, Cox D and Pelletier D. Association between stressful life events and exacerbation in multiple sclerosis: a meta-analysis. Bmj. 2004; 328: 731.

9. Huitinga I, Erkut ZA, van Beurden D and Swaab DF. Impaired hypothalamus-pituitaryadrenal axis activity and more severe multiple sclerosis with hypothalamic lesions. Annals of neurology. 2004; 55: 37-45.

10. Huitinga I, Erkut ZA, van Beurden D and Swaab DF. The hypothalamo-pituitary-adrenal axis in multiple sclerosis. Annals of the New York Academy of Sciences. 2003; 992: 118-28.

11. Reder AT, Makowiec RL and Lowy MT. Adrenal size is increased in multiple sclerosis. Archives of neurology. 1994; 51: 151-4.

12. Erkut ZA, Hofman MA, Ravid R and Swaab DF. Increased activity of hypothalamic corticotropin-releasing hormone neurons in multiple sclerosis. Journal of neuroimmunology. 1995; 62: 27-33.

13. Erkut ZA, Endert E, Huitinga I and Swaab DF. Cortisol is increased in postmortem cerebrospinal fluid of multiple sclerosis patients: relationship with cytokines and sepsis. Multiple sclerosis. 2002; 8: 229-36.

14. Grant I, Brown GW, Harris T, McDonald WI, Patterson T and Trimble MR. Severely threatening events and marked life difficulties preceding onset or exacerbation of multiple sclerosis. Journal of neurology, neurosurgery, and psychiatry. 1989; 52: 8-13.

15. Liu XJ, Ye HX, Li WP, Dai R, Chen D and Jin M. Relationship between psychosocial factors and onset of multiple sclerosis. European neurology. 2009; 62: 130-6.

16. Li J, Johansen C, Bronnum-Hansen H, Stenager E, Koch-Henriksen N and Olsen J. The risk of multiple sclerosis in bereaved parents: A nationwide cohort study in Denmark. Neurology. 2004; 62: 726-9.

17. Riise T, Mohr DC, Munger KL, Rich-Edwards JW, Kawachi I and Ascherio A. Stress and the risk of multiple sclerosis. Neurology. 2011; 76: 1866-71.

18. Warren S, Greenhill S and Warren KG. Emotional stress and the development of multiple sclerosis: case-control evidence of a relationship. Journal of chronic diseases. 1982; 35: 821-31.

19. Palumbo R, Fontanillas L, Salmaggi A, La Mantia L and Milanese C. Stressful life events and multiple sclerosis: a retrospective study. Ital J Neurol Sci. 1998; 19: 259-60.

20. Lucas RM, Ponsonby AL, Dear K, et al. Sun exposure and vitamin D are independent risk factors for CNS demyelination. Neurology. 2011; 76: 540-8.

21. Holmes TH and Rahe RH. The Social Readjustment Rating Scale. Journal of psychosomatic research. 1967; 11: 213-8.

22. Scully JA, Tosi H and Banning K. Life event checklists: Revisiting the social readjustment rating scale after 30 years. Educ Psychol Meas. 2000; 60: 864-76. 
23. Lucas RM, Ponsonby AL, Dear K, et al. Associations between Silicone Skin Cast Score, Cumulative Sun Exposure, and Other Factors in the Ausimmune Study: A Multicenter Australian Study. Cancer Epidemiol Biomarkers Prev. 2009; 18: 2887-94.

24. Levin LI, Munger KL, Rubertone MV, et al. Multiple sclerosis and Epstein-Barr virus. Jama. 2003; 289: 1533-6.

25. Halberg F. Chronobiology. Annu Rev Physiol. 1969; 31: 675-725.

26. Spitzer C, Bouchain M, Winkler LY, et al. Childhood trauma in multiple sclerosis: a casecontrol study. Psychosom Med. 2012; 74: 312-8.

27. Burns MN, Nawacki E, Kwasny MJ, Pelletier D and Mohr DC. Do positive or negative stressful events predict the development of new brain lesions in people with multiple sclerosis? Psychological medicine. 2014; 44: 349-59.

28. Statistics ABo. Census of Population and Housing 2006. Canberra: Australian Bureau of Statistics. 2008. 


\begin{tabular}{|c|c|c|c|c|}
\hline & $\begin{array}{c}\text { FDE cases } \\
(n=216)\end{array}$ & $\begin{array}{l}\text { FDE controls } \\
(n=398)\end{array}$ & $\begin{array}{l}\text { FCD cases } \\
(n=282)\end{array}$ & $\begin{array}{l}\text { FCD controls } \\
\qquad(\mathrm{n}=558)\end{array}$ \\
\hline Female $(\% ; n / N)$ & $76.9(166 / 216)$ & $77.6(309 / 398)$ & $76.6(216 / 282)$ & $78.1(436 / 558)$ \\
\hline Mean age at review (SD; range) & $37.5(9.4 ; 18.1-58.4)$ & $38.6(9.3 ; 19.3-60.9)$ & $38.6(9.8 ; 18.2-58.4)$ & $38.6(9.8 ; 18.1-58.4)$ \\
\hline Mean FDE age (SD; range) & $36.8(9.4 ; 18-58)$ & - & \multicolumn{2}{|c|}{$38.5(9.7 ; 18868)(9.7 ; 18-60)$} \\
\hline $\begin{array}{l}\text { Median Total Stress Number } \\
(\mathrm{IQR})^{*}\end{array}$ & $2(1,3)$ & $2(1,3)$ & $2(1,3)$ & $2(1,3)$ \\
\hline $\begin{array}{l}\text { Median Total Stress Load } \\
(\mathrm{IQR})^{* *}\end{array}$ & $65(26,121)$ & $57(22,106)$ & $61(22,118)$ & $60(22,108)$ \\
\hline Low actinic damage $(\leq 3)(\mathrm{n}(\%))$ & $21.9(46 / 210)$ & $17.7(68 / 385)$ & $22.1(60 / 272)$ & $19.7(106 / 537)$ \\
\hline $\begin{array}{l}\text { Low } 25(\mathrm{OH}) \text { D levels at FDE } \\
\text { onset }(\leq 50 \mathrm{nmol} / \mathrm{L})(\% \mathrm{n} / \mathrm{N})\end{array}$ & $21.5(44 / 209)$ & $14.3(53 / 372)$ & $20.2(55 / 272)$ & $13.9(72 / 520)$ \\
\hline $\begin{array}{l}\text { Ever had infectious } \\
\text { mononucleosis (Yes \% n/N) }\end{array}$ & $26.3(56 / 213)$ & $17.3(68 / 394)$ & $26.7(74 / 277)$ & $16.6(92 / 533)$ \\
\hline Ever smoked $($ Yes \% n/N) & $62.9(134 / 213)$ & $53.4(210 / 393)$ & $62.1(172 / 277)$ & $53.3(294 / 552)$ \\
\hline $\begin{array}{l}H L A-D R 15 \text { positive (rs9271366: } \\
\text { GG or } A G \% \mathrm{n} / \mathrm{N})\end{array}$ & $53.9(103 / 191)$ & $29.1(96 / 330)$ & $55.7(136 / 244)$ & $29.4(131 / 445)$ \\
\hline
\end{tabular}

FDE=First demyelinating event; $\mathrm{FCD}=$ first clinical diagnosis of demyelination. 
Table 2. The association between the different types of stressful life events in the previous 12 months and risk of first demyelinating event.

\begin{tabular}{|c|c|c|c|c|c|c|}
\hline \multirow[b]{2}{*}{ Type of stressful life event } & \multirow[b]{2}{*}{$\begin{array}{l}\text { FDE cases } \\
\% \\
(\mathrm{n} / \mathbf{2 1 3})\end{array}$} & \multirow[b]{2}{*}{$\begin{array}{l}\text { FDE controls } \\
\% \\
(\mathrm{n} / 393)\end{array}$} & \multicolumn{4}{|c|}{$\begin{array}{l}\text { Reference group includes those without the particular type of } \\
\text { stressful life event }\end{array}$} \\
\hline & & & $\begin{array}{l}\text { Unadjusted odds } \\
\text { ratio }(95 \% \mathrm{CI})\end{array}$ & P-value & $\begin{array}{l}\text { Adjusted odds } \\
\text { ratio }(95 \% \mathrm{CI}) *\end{array}$ & p-value \\
\hline $\begin{array}{l}\text { Your parent, child or partner } \\
\text { died }\end{array}$ & $3.3(7)$ & $4.1(16)$ & $0.88(0.35,2.20)$ & 0.78 & $1.18(0.35,3.96)$ & 0.78 \\
\hline Your friend or relative died & $25.4(54)$ & $31.6(124)$ & $0.72(0.49,1.06)$ & 0.10 & $0.83(0.53,1.28)$ & 0.39 \\
\hline $\begin{array}{l}\text { You suffered from a serious } \\
\text { illness } * *\end{array}$ & $15.6(33)$ & $7.4(29)$ & $2.35(1.36,4.06)$ & 0.002 & $2.24(1.21,4.16)$ & 0.01 \\
\hline Serious injury or assault & $5.2(11)$ & $6.4(25)$ & $0.83(0.37,1.86)$ & 0.65 & $0.75(0.29,1.95)$ & 0.56 \\
\hline $\begin{array}{l}\text { A serious injury or assault } \\
\text { happened to a friend }\end{array}$ & $24.5(52)$ & $22.4(88)$ & $1.12(0.75,1.67)$ & 0.58 & $1.49(0.93,2.38)$ & 0.09 \\
\hline $\begin{array}{l}\text { You or your parents broke off a } \\
\text { serious relationship }\end{array}$ & $10.3(22)$ & $8.7(34)$ & $1.24(0.71,2.19)$ & 0.44 & $1.03(0.54,1.98)$ & 0.92 \\
\hline $\begin{array}{l}\text { You became pregnant or } \\
\text { menopausal }\end{array}$ & $11.4(24)$ & $16.0(62)$ & $0.63(0.38,1.05)$ & 0.07 & $0.76(0.42,1.36)$ & 0.35 \\
\hline $\begin{array}{l}\text { You became engaged, married or } \\
\text { resumed a steady relationship }\end{array}$ & $8.5(18)$ & $9.7(38)$ & $0.89(0.46,1.66)$ & 0.69 & $0.86(0.41,1.81)$ & 0.70 \\
\hline $\begin{array}{l}\text { You had problems with the } \\
\text { police and a court appearance }\end{array}$ & $5.2(11)$ & $2.8(11)$ & $1.63(0.70,3.82)$ & 0.26 & $1.19(0.45,3.16)$ & 0.73 \\
\hline $\begin{array}{l}\text { You were sacked from your job } \\
\text { or expelled from school }\end{array}$ & $3.3(7)$ & $2.3(9)$ & $1.18(0.42,3.37)$ & 0.75 & $0.80(0.21,2.80)$ & 0.73 \\
\hline $\begin{array}{l}\text { You had a crisis of serious } \\
\text { disappointment in your work, } \\
\text { school or career. }\end{array}$ & $16.0(34)$ & $14.8(58)$ & $1.05(0.64,1.73)$ & 0.83 & $1.23(0.68,2.23)$ & 0.50 \\
\hline $\begin{array}{l}\text { You gained a new family } \\
\text { member }\end{array}$ & $20.2(43)$ & $16.8(66)$ & $1.27(0.81,1.97)$ & 0.29 & $1.50(0.91,2.49)$ & 0.11 \\
\hline You had a major financial crisis & $7.0(15)$ & $8.4(33)$ & $0.74(0.38,1.45)$ & 0.38 & $0.59(0.27,1.30)$ & 0.19 \\
\hline You changed house, school or & $33.3(71)$ & $30.8(121)$ & $1.15(0.80,1.67)$ & 0.44 & $1.19(0.78,1.83)$ & 0.42 \\
\hline
\end{tabular}


You changed your personal

$19.7(42)$

$15.0(59)$

$1.39(0.90,2.16)$

0.14

$1.17(0.70,1.97)$

0.55

habits, including use of alcohol

or drugs.

You had an outstanding personal 14.1 (30)

$12.1(48)$

$1.53(0.82,2.87)$

0.19

$1.10(0.62,1.93)$

0.75

*Adjusted for physical activity

** Participants were asked to exclude any illness leading to study participation. 

Table 3. The association of different categories* of stressful life events in the previous 12 months and risk of a first demyelinating event.

\begin{tabular}{|c|c|c|c|c|}
\hline \multirow[b]{2}{*}{ Stressful life event category* } & \multicolumn{4}{|c|}{$\begin{array}{l}\text { Reference group includes those without the particular type of stressful life } \\
\text { event }\end{array}$} \\
\hline & $\begin{array}{l}\text { Unadjusted odds ratio } \\
\qquad(95 \% \mathrm{CI})\end{array}$ & P-value & $\begin{array}{l}\text { Adjusted odds ratio } \\
\qquad(95 \% \mathrm{CI}) * *\end{array}$ & P-value \\
\hline $\begin{array}{l}\text { Death of a close family member or } \\
\text { friend }\end{array}$ & $0.76(0.52,1.12)$ & 0.16 & $0.90(0.58,1.39)$ & 0.64 \\
\hline $\begin{array}{l}\text { Personal illness/injury or } \\
\text { illness/injury of a close family } \\
\text { member or friend }\end{array}$ & $1.50(1.05,2.16)$ & 0.025 & $1.88(1.23,2.88)$ & $<0.01$ \\
\hline $\begin{array}{l}\text { Interaction problems with family } \\
\text { other than spouse }\end{array}$ & $1.27(0.82,1.97)$ & 0.29 & $1.50(0.91,2.49)$ & 0.11 \\
\hline Marital related stress & $1.19(0.74,1.89)$ & 0.48 & $1.02(0.59,1.77)$ & 0.93 \\
\hline Pregnancy related stress & $0.63(0.38,1.05)$ & 0.08 & $0.76(0.42,1.36)$ & 0.35 \\
\hline Work-related stress & $1.02(0.63,1.65)$ & 0.94 & $1.19(0.67,2.12)$ & 0.56 \\
\hline Financial related stress & $0.74(0.38,1.45)$ & 0.38 & $0.59(0.27,1.30)$ & 0.19 \\
\hline Lifestyle changes & $1.33(0.94,1.89)$ & 0.12 & $1.25(0.83,1.86)$ & 0.29 \\
\hline Miscellaneous & $1.23(0.75,2.02)$ & 0.41 & $1.10(0.62,1.93)$ & 0.75 \\
\hline \multicolumn{5}{|c|}{$\begin{array}{l}\text { *Group } 1 \text { (Death of family member or friend) includes "Your parent, child or partner died" and "Your friend or relative died"; Group } 2 \\
\text { (Illness/injury) includes "You suffered from a serious illness*", "Serious injury or assault", and "A serious injury or assault happened to a friend"; } \\
\text { Group } 3 \text { (Family interaction) includes "You gained a new family member"; Group } 4 \text { (Marital status) includes "You or your parents broke off a } \\
\text { serious relationship", and "You became engaged, married or resumed a steady relationship"; Group } 5 \text { (Pregnancy) includes "You became pregnant or } \\
\text { menopausal"; Group } 6 \text { (Work related events) includes "You were sacked from your job or expelled from school", and "You had a crisis of serious } \\
\text { disappointment in your work, school or career"; Group } 7 \text { (Financial issues) includes "You had a major financial crisis"; Group } 8 \text { (Lifestyle changes) } \\
\text { includes "You changed house, school or jobs", and "You changed your personal habits, including use of alcohol or drugs"; Group } 9 \text { (Miscellaneous) } \\
\text { includes "You had an outstanding personal achievement" } \\
\text { ** Adjusted for physical activity }\end{array}$} \\
\hline
\end{tabular}


Table 4. The association between stress number and load in the previous 12 months and risk of first demyelinating event.

\begin{tabular}{|c|c|c|c|c|c|c|}
\hline & $\begin{array}{l}\text { FDE cases } \\
\%(n)\end{array}$ & $\begin{array}{l}\text { FDE controls } \\
\%(n)\end{array}$ & $\begin{array}{l}\text { Matched odds } \\
\text { ratio (95\% CI) }\end{array}$ & p-value & $\begin{array}{l}\text { Adjusted odds } \\
\text { ratio }(95 \% \mathrm{CI}) *\end{array}$ & p-value \\
\hline \multicolumn{7}{|l|}{ Stress number } \\
\hline 0 events & $16.0(34)$ & $19.6(77)$ & $1.00(\operatorname{Ref})$ & - & 1.00 (Ref) & - \\
\hline 1 event & $22.1(47)$ & $25.7(101)$ & $1.04(0.61,1.76)$ & 0.89 & $1.26(0.68,2.32)$ & 0.46 \\
\hline 2 events & $24.4(52)$ & $23.7(93)$ & $1.23(0.71,2.15)$ & 0.46 & $1.58(0.81,3.09)$ & 0.18 \\
\hline 3 or more events & $37.6(80)$ & $31.0(122)$ & $1.44(0.87,2.38)$ & 0.16 & $1.83(0.99,3.36)$ & 0.05 \\
\hline Test for trend & & & & 0.10 & & 0.04 \\
\hline \multicolumn{7}{|l|}{ Stress load } \\
\hline 0 & $16.0(34)$ & $19.6(77)$ & $1.00(\operatorname{Ref})$ & - & $1.00($ Ref $)$ & - \\
\hline $1-75$ & $39.4(84)$ & $41.0(161)$ & $1.14(0.70,1.85)$ & 0.60 & $1.40(0.79,2.49)$ & 0.25 \\
\hline $76-150$ & $30.5(65)$ & $27.5(101)$ & $1.33(0.79,2.25)$ & 0.28 & $1.69(0.89,3.20)$ & 0.11 \\
\hline$>150$ & $14.1(30)$ & $12.0(47)$ & $1.40(0.76,2.59)$ & 0.28 & $1.66(0.80,3.42)$ & 0.17 \\
\hline Test for trend & & & & 0.18 & & 0.13 \\
\hline
\end{tabular}

*Adjusted for physical activity 
*Total Stress Number $=$ sum of events experienced (e.g. event type $1+$ event type $2+$ event type $3=$ Total Number of Stress

Events)

** Total Stress Load $=$ sum of stress weight assigned to event (e.g. event type 1 assigned weight + event type 2 assigned weight $=$ Total Stress Load experienced) 